\title{
Production and Quality Characterization of Fuel Briquette Manufactured from Khat Waste: A Case Study
}

\author{
Kuma Teru Rorisa ${ }^{1}$ A. Balasuadhakar ${ }^{2}$ and K. Balasundaram ${ }^{3}$ \\ ${ }^{1-3}$ School of Mechanical and Industrial Engineering
}

Dire Dawa Institute of Technology

Dire Dawa University, Ethiopia

\begin{abstract}
This study aimed to produce fuel briquettes from khat waste at Dire Dawa Ethiopia, which is the most serious invasive plant waste, spreading throughout the world particularly at an alarming rate in Ethiopia. Utilization of biomass like invasive waste plant such as khat waste in Ethiopia has a greater advantage for the discovery of clean renewable energy sources and for reduction of deforestation of indigenous trees. Producing the fuel briquetting of khat waste branch and the raw material of khat waste branch of the plant is carried out by using ASTM procedure. The mean average value for fixed carbon content (FCC) and calorific value of the khat waste branch of fuel briquette of the sample were $39.268 \%$ and $4143.269(\mathrm{cal} / \mathrm{g})$ respectively. Also, the result for fixed carbon content(FCC) and calorific value of khat waste branch of raw material waste $20.9 \%$ and $3688.3946(\mathrm{cal} / \mathrm{g})$ respectively. The finding shows that by eco-friendly utilization of khat waste plant as a clean energy fuel briquette. It is possible to manage the spread of such type alien invasive plant as well as to increase farmer's crop production, access for livestock grazing land; reduce deforestation of indigenous trees and reduce indoor air pollution.
\end{abstract}

Keywords: Biomass, Briquette, Fuel quality, khat waste branch.

\section{INTRODUCTION}

Higher standard of living as well as population growth has resulted in an increasing demand of food and new form of clean energy throughout the world. Energy is a vital input for development and an essential ingredient for the survival of humankind. Among the major energy issues today are that of energy security, environmental implication of fossil fuel consumption and deforestation. Among the clean energy source, the use of biomass resource can be one alternative energy resource, since energy from biomass waste is a proven renewable energy technology that recovers energy from waste. However, the use of biomass energy sources in most developing countries including Ethiopia is mostly traditional that lead to indoor air pollution as a result causes health and environmental problems. In Ethiopia, the issues of energy security and municipal solid waste management are more prominent. Ethiopia relies mainly on traditional biomass burning supplies more than $85 \%$ of national energy consumption. This has been causing different environmental and socio-economic impacts. In contrary, there is no denying that non-oil resource countries like Ethiopia, is bound to face a severe energy crisis in the near future because of its over dependence on imported fuel. Therefore, there is huge demand for the development of alternative biomass energy technologies in Ethiopia to utilize biomass wastes to energy through the popularization of the briquetting technology, among others. The briquetting process is the physical transformation of loose raw organic materials into high-density fuel briquettes through a compacting process, which increases the calorific value, and combustion efficiency of the product. In Ethiopia, the available biomass resource such as wood, agroindustrial residues and municipal waste, which is expected to meet the country's growing energy demand, can provide huge opportunity for the adoption of the briquetting technology. The manufacture, repair and maintenance of briquette equipments can be addressed using local capacity. Thus, there is a need for strengthening cooperation among all stakeholders concerned with energy and environment to promote the briquetting technology there by contribute towards efficient and environmentally sustainable energy supply.

Historically, biomass has been a major source of household's energy in Ethiopia community. Biomass meets the cooking energy needs of most rural households and half of the urban household's demands. Despite significant adoption of commercial energy in 
Ethiopia during last few decades, biomass continues to dominate energy supply in rural and traditional sectors. Biomass energy constitutes wood fuels (including charcoal, and wood wastes), crop residues (such as coffee husk, bagasse, rice husk and crop stalks) and animal dung (including biogas). Ethiopia's energy system is characterized mainly by biomass fuel supply, which covers $85 \%$ of the energy consumption, with households being the greatest energy consumers [2]. The heavy dependence on traditional biomass in Dire Dawa is leading to different environmental and socio-economic problems including deforestation, soils erosion, water pollution, and indoor air pollution, deforestation and most importantly deforestation which affecting the limited forest resources of the country (Lakewet al., 2011; Bekeleet al., 2013; Bizzarri, 2010). In addition dependence on biomass energy involves a trade-off in agricultural productivity, the crop residues and animal wastes being diverted from farms, where they supplement soil nutrition, to provide energy needs. Furthermore, the growing demand for traditional use of biomass energy and lack of access to modern energy services is expected to impose pressure on the limited biomass and forest stock of the country. Hence there is a need for the adoption and promotion of alternative modern biomass conversion technologies that can result in more efficient and eco-friendly energy supply. [5]

Worldwide, both technologies are being used for briquetting of sawdust and locally available agro-residues. Although the importance of biomass briquettes as substitute fuel for wood, coal and lignite is well recognized, the numerous failures of briquetting machines in almost all developing countries have inhibited their extensive exploitation. Briquetting technology is yet to get a strong foothold in many developing countries because of the technical constraints involved and the lack of knowledge to adapt the technology to suit local conditions. Overcoming the many operational problems associated with this technology and ensuring the quality of the raw material used are crucial factors in determining its commercial success. In addition to this commercial aspect, the importance of this technology lies in conserving wood, a commodity extensively used in developing countries and leading to the widespread destruction of forests. Therefore, municipal solid waste management is one of huge challenge around and in Dire Dawa city. Initiative for the current research came from city administration, mainly small and medium enterprise, environment and energy offices were interested in the treatment of municipal waste into compacted forms suitable for gasification. Utilization of municipal waste such as "chat wastes" as a substitute renewable alternative energy-carrier to reduce deforestation, environmental pollution and flooding due to clogging of ditches and drainage by the wastes is very advantageous from economic as well as from ecological point of view. The basic ecological reason for stopping disposal of chat wastes on ditches and drainage, and deposition of the combustible waste in dumps is the fact that led to flooding during raining season and biological decomposition process forms methane gas, which is harmful for the environment. Methane as a greenhouse effect gas is 23 times more harmful than carbon oxide [15]. The energetic value of non-recyclable municipal waste can be recovered by gasification process.

\section{LITERATURE REVIEW}

In Ethiopia, Khat has other local names such as "Beleche", “Aweday", "Abo Mismar", "Gelemso", "Bahirdar" and others based on place of cultivation. Because of the chemical profile of khat leaves determined by the environmental and climate conditions, the stimulating power and cost of the product varies depending on its source. It was claimed that the "Aweday" and "Abo Mismar" varieties, which are cultivated in Harar highlands of Eastern Ethiopia are the most potent and costly among the local brands and hence are chosen for export (Belew, 2000; Gebissa, 2008). The leaves have an aromatic odor, astringent \& slightly sweet taste. The scientific study shows the following biological classification, scientific name synonyms, common names or taxonomic position: division Khat, Catha Edulis, Chat,Qat, Mirra, Chat in Ethiopia . Figure 1 show that chat in Ethiopia.

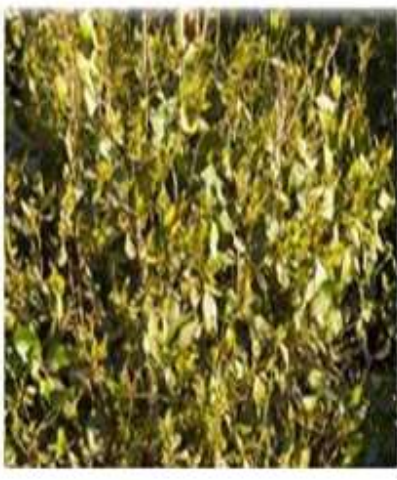

A

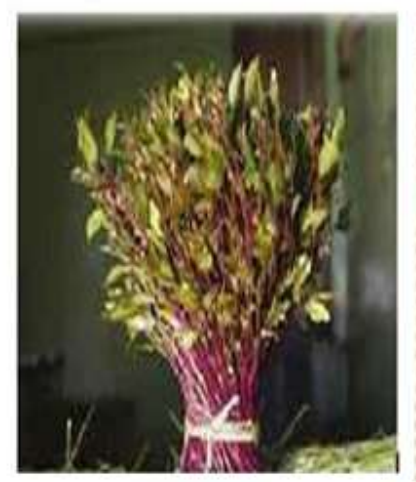

B

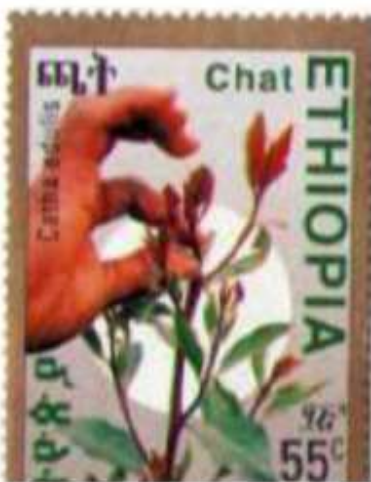

C

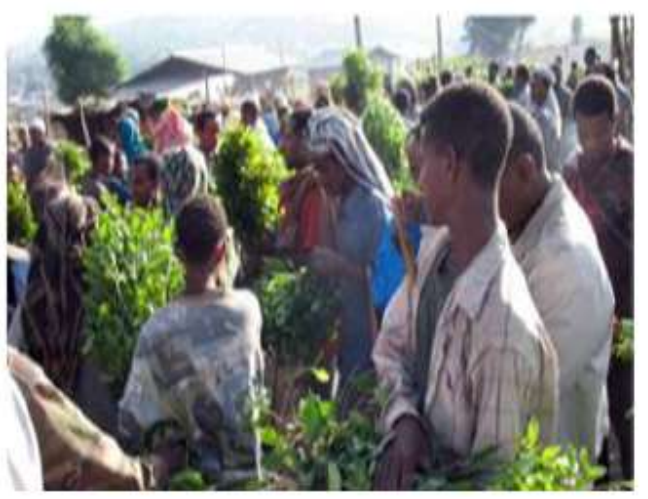

$\mathrm{D}$

Figure 1: Chat in Ethiopia.

(A) "Chat" cultivation, (B) Bundle of "Chat", (C) Postal stamp, and (D) "Chat" market in Hayik, Wollo, Ethiopia.

Historically, the original source of khat seems to be obscure. However, there is general agreement that its use was prevalent in Ethiopia and from there, around the 15th century, the practice spread to the south-west of the Arabian Peninsula (Peters, 1952 and Radt, 1969 (By ZewduMinwuyelet G/Mariam)). Later on it also grows in Somalia, Kenya, Malawi, Uganda, Tanzania, Congo, Zambia, Zimbabwe, Afghanistan, Yemen and Madagascar. It is estimated that about 20 million people consume khat leaves 
around the world. Every day, an estimated six million people chew khat all over the world (Odenwald et al., 2005). Its use traditionally has been confined to the regions where it is grown, because only the fresh leaves have the desired stimulating effects. However, in recent years it becomes more common in western countries due to migration of people from those 13 endemic khatchewing countries like Ethiopia, Somalia and access of air transportation have increased. The global distribution of this perishable commodity, and as a result, the plant has been reported in Amsterdam, Australia, Canada, England, Israel, Rome, New Zealand, Wales, and the United States. The effects of khat chewing were reported as early as 1237 by the Arabian physician Naguib Ad din (Lebras and Fretillere, 1965), who proposed the use of khat for the treatment of depressive states. By the same year, other writers also reported that it was effective in blunting the sensation of hunger and fatigue (Krikorian, 1984; Lebras and Fretillere, 1965). People chew chat since khat contains psychoactive components namely, Cathinone and Cathine which are able to stimulate CNS, increases locomotors activity and results in sympathomimetic effect which are analogous to the effects of amphetamine (Kalix, 1990). Because of their psycho-stimulant properties, fresh, young shoot and tender leaves of khat are commonly chewed in eastern Africa and Arabian Peninsula countries for hundreds of years to attain a state of euphoria as well as to alleviate fatigue, enhance work capacity, stay alert, reduce hunger, and to enhanced self-esteem (Nasrulla, 2000; Al-Kamel, 2001; Ageely, 2009; Luqman, 1976). Yemeni khat chewers also believe that khat is beneficial for treatment of minor ailments such as headaches, colds, body pains, fevers, arthritis and also depression (Kennedy, et al., 1983). Workers on night shifts also use it to stay awake and postpone fatigue. Students have chewed khat in an attempt to improve mental performance before exams. It is habitually used in informal meetings (khat sessions) in which the participants are engaged in discussions and maintain social contact. Due to that, Khat chewing usually takes place in groups in a social setting. Only a minority frequently chew alone. The psycho stimulant component of khat, which is Cathinone, released within 15-45 min during chewing (Graziani et al., 2008). Following this, the user can experience an increase in blood pressure and heart rate, anorexia, insomnia, alertness, elevated mood and loquacity (Al-Mamary et al., 2002). Furthermore, chronic khat chewing for many years results in unpleasant effect of cognitive defects and psychosis associated with severe neurological illness.[23]

\section{MATERIALS AND METHODS}

In this study, the biomasses of khat wastes were collected as a source for briquette production and from in Dire Dawa city, Ethiopia. The sample of khat waste would take from its branch part and dry at air temperature. The collected sample was chopped to dimension that fit the carbonization metal kiln. Then it was transported to Alternative energy development and promotion laboratory and workshop center, Ministry of water, irrigation and energy (MOWIE), Addis Ababa, for carbonization, determination of proximate analysis, bulk density and calorific value of the briquette. Figure 2 show that map of the study area, from Google.

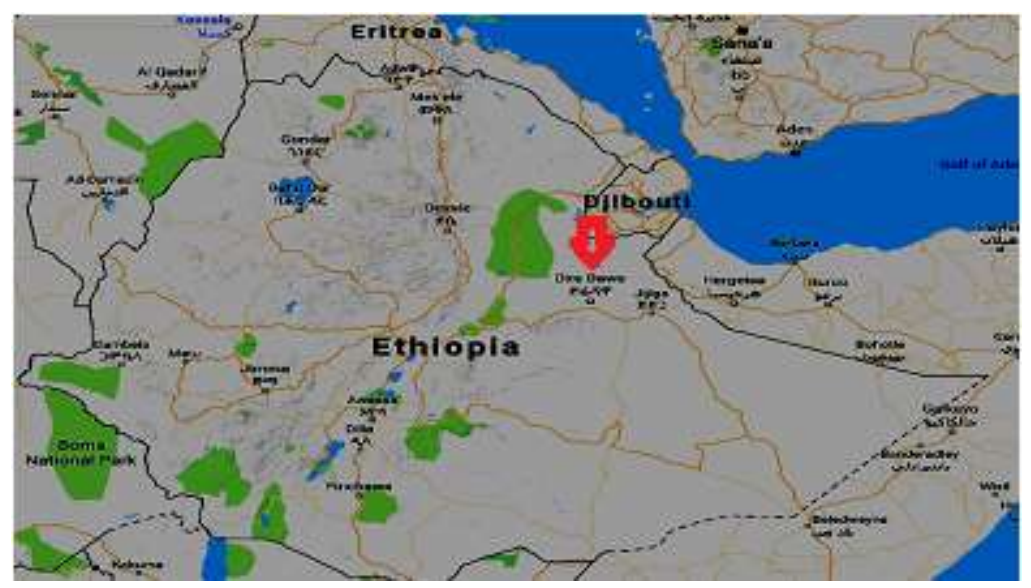

Figure2: Map of the study area, from Google

In this study khat waste fuel briquette was evaluated for its fuel briquette quality by fuel quality determining parameter expressed in terms of proximate analysis and physical properties. The amount of wastage found at the selected site is obtain from questioner paper by asking questions the khat sellers that percentage of waste found from their daily sell. Samples would collected from site, with appropriate safety using like glove then sorted with its type such as branch then chopped with proper size to fit the kiln for carbonization processes and dried for a fifteen days. The carbonization process proceed with proper way feeding to the kiln and cleaning of the kiln followed by proper controlling of the air for proper dehydration and carbonization and following the chimney smoke type and closing the whole opening that show completion of carbonization and cooling to proceeded. The amount of khat wastage disposal calculated from the total amount khat entered to city time's percentage of total wastage obtained from questioner divided to total amount khat from questioner. In addition, the total amount wastage after drying is calculated by multiplying monthly wastage before dry by sample after dry divided to sample before dry. In addition, the amount of charcoal calculated by multiplying wastage dried by sample charcoal divided to sample dried. Finally, total amount of briquette is calculated by 
multiplying total amount charcoal monthly from selected site by amount briquette from sample divided to amount of charcoal from sample. Table 1 shows that date required completing the above equation.

Table 1. Two types of data prepared to manufacture sample briquette.

\begin{tabular}{|l|l|}
\hline \multicolumn{1}{|c|}{ A. Sample data } & \multicolumn{1}{c|}{ B. Questioner data result } \\
\hline Amount of waste before drying $(\mathrm{kg})$ & Total amount of khat from seller $(\mathrm{kg})$ \\
Amount of waste after drying $(\mathrm{kg})$ & Total amount of wastage from seller $(\mathrm{kg})$ \\
Amount of charcoal produced from & Average wastage in $(\%)$ \\
waste combustion (kg) & \\
Drying time (day) & \\
Amount of binder (clay) (kg) & \\
Amount of briquette from sample (pcs) & \\
\end{tabular}

\subsection{Fuel Briquette Production Process and Physical properties}

Briquetting charring procedures includes crushing of charred biomass to finer particles, mixing of char dust with binder and the actual densification or briquetting process using beehive coal briquette machine press mold with 2000 briquettes per hour capacity. The overall production process starts with collecting of the biomass khat waste, which was used as raw material and sun drying for more than 15 days after chopping to obtain homogeneous size for carbonization then branch with trunk of khat waste were placed in barrel kiln about dried sample $11.017 \mathrm{~kg}$. In this study, the process of carbonization were carried out in oxygenlimited condition in barrel kiln which have long chimney; which used to control the proper air for carbonization process. Then with screw when dehydration completed just when cloudy smoke become closely to blue or black so as limited oxygen environment was created and the chimney also covered by clay mud for charcoal production and cooling in controlled manner. The resulted charcoal were ground to fine particles by using charcoal grinder or charcoal mill to produce charcoal powder which is about $3.025 \mathrm{~kg}$. The proximate analysis of the raw material (moisture content, ash content, volatile matter content, and fixed carbon content) was conducted following ASTM D-standards. To determine calorific value, , the briquette specimens were milled with 1.0633 gram and then placed in a capsule and combusted in and analyzed by an adiabatic oxygen bomb calorimeter Parr 6200-calorie meter of Parr M39889 and Parr M39805 oxygen bomb, which were used following the Parr instruction manual according to(ASTM D-5865-95, 1996) and calorific values were measured. The bulk density was determined by placing the charcoal powdered in metal cub with size of cub $\mathrm{x}=\mathrm{y}=\mathrm{z}$ dimension and then the weight of powdered measured and the result computed as the weight of charcoal divided by the volume of the container.

All proximate analysis of the produced fuel briquette includes moisture content, Volatile matter content, ash content and fixed carbon content were carried out in the Alternative Energy Development and Promotion Directorate Laboratory, MOWIE, Addis Ababa, Ethiopia and all proximate analysis were carried out accordance with (ASTM D-1762-84, 1996) protocol. The physical property of the produced khat waste fuel briquette like bulk density, calorific value and weight $(\mathrm{g})$ immediate after removal from briquette machine and up to 15 days were done in the same laboratory, Alternative energy development and promotion directorate; MOWIE. Beside this all physical property test durability, the cooking time of fuel briquette or time taken to turn ash and time taken to boil for 1L and 2 litter water also carried out with so called „Merichaye ${ }^{\text {ee }}$ briquette stove. The stove is designed and produced in Alternative energy development and promotion directorate of MOWIE, Ethiopia

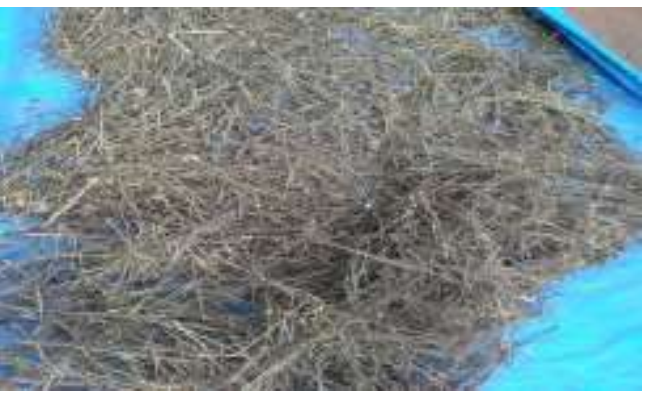

A

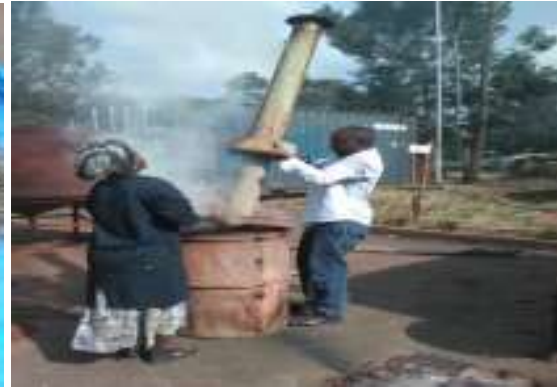

B

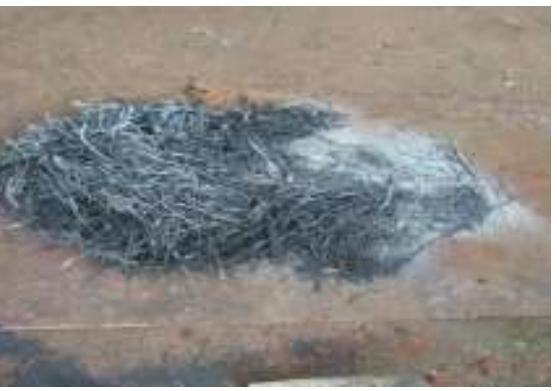

C 


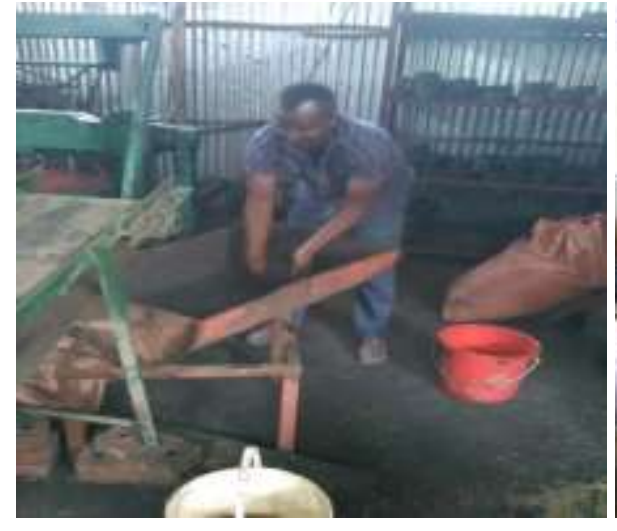

D

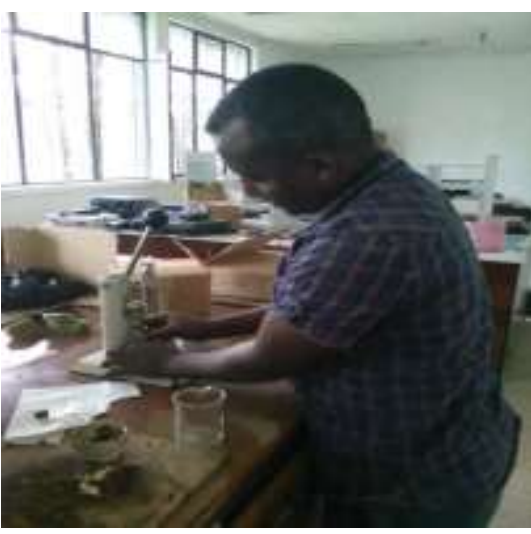

E

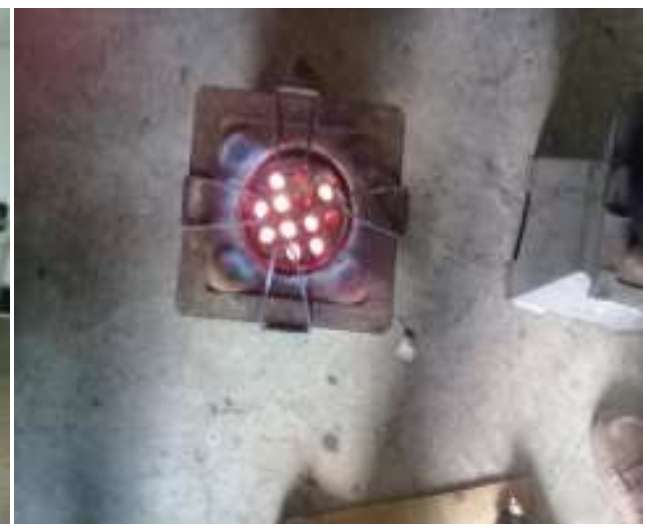

$\mathrm{F}$

Figure 3. Preparation briquette production

(A) sample preparation for khat production (B) combustion of wastage for briquetting (C) carbonization of khat waste in barrel kiln and it result (D) Binding of charcoal with binder and manufacture of briquette (E) laboratory testing for khat waste product $(F)$ sample preparation and boiling test of khat waste briquette

\section{RESULTS AND DISCUSSIONS}

The quality determining parameter of briquette and charcoal produced from biomasses expressed in terms of proximate analysis and physical properties. Since, these parameters such as moisture content (MC), volatile matter (VM), ash content (AC), fixed carbon content (FC), calorific value (CV), bulk density (BD) and sulphur content (SC) were verifying the quality of briquette to decide for utilization. Hence, characterization of briquette for their proximate and physical properties is very important.

\subsection{Moisture content}

The moisture content of the charcoal determine the physical properties of the briquettes consequently, if the moisture content is low the briquette will have resistance to biodegradation and less vulnerable to the attack of biological agents as well as not flexible to atmospheric conditions and it becomes durable. If briquette charcoal containing high of moisture content will lead to the swelling and the disintegration of the briquette charcoal. Normally, fresh charcoal from an opened kiln contains very little moisture content, which, is usually less than $1 \%$. But it can absorb the moisture content from the humidity of air itself rapidly with time, a gain of moisture even without any rain wetting and even the charcoal in well burned situation can take the moisture content about 5 to $10 \%$. As we have seen from Table 2 below the moisture content of briquettes produced from branch of khat waste were lower than the moisture content of briquette produced from wood which has moisture content of $12 \%$ by using three samples each have 3-gram weight and oven dried at 105ocfor four hours. Therefore, the result of raw material with different mass of conic shape cup as shown below in detail. The quality specification of charcoal usually limits the moisture content between 5 to $15 \%$ (FAO, 1985); (FAO, 1999) while the good quality of charcoal should have the moisture content is $10 \%$ maximum. On the other hand, there is some evidence concerned that charcoal with high moisture content at $10 \%$ or more than $10 \%$ tends to shatter when heated in the blast furnace (FAO, 1987). In this study the result khat waste branch charcoal table 2 above showed moisture contents of raw material $7.2 \%$, moisture content of charcoal $5 \%$ and its briquette moisture is $6.4 \%$, which is fit within the; desirable criteria set by (FAO, 1987).Moisture contents of the raw material, charcoal and briquette of khat waste was as shown in Figure 4.

Table2. Moisture content of raw material, charcoal and briquette

\begin{tabular}{|c|c|c|}
\hline No & MC tested & MC value (\%) \\
\hline 1 & $\begin{array}{c}\text { Moisture Content of Raw } \\
\text { material(MCR) }\end{array}$ & 7.2 \\
\hline 2 & $\begin{array}{c}\text { Moisture Content of } \\
\text { Charcoal (MCC) }\end{array}$ \\
\hline 3 & $\begin{array}{c}\text { Moisture Content of } \\
\text { Briquette(MCB) }\end{array}$ \\
\hline
\end{tabular}




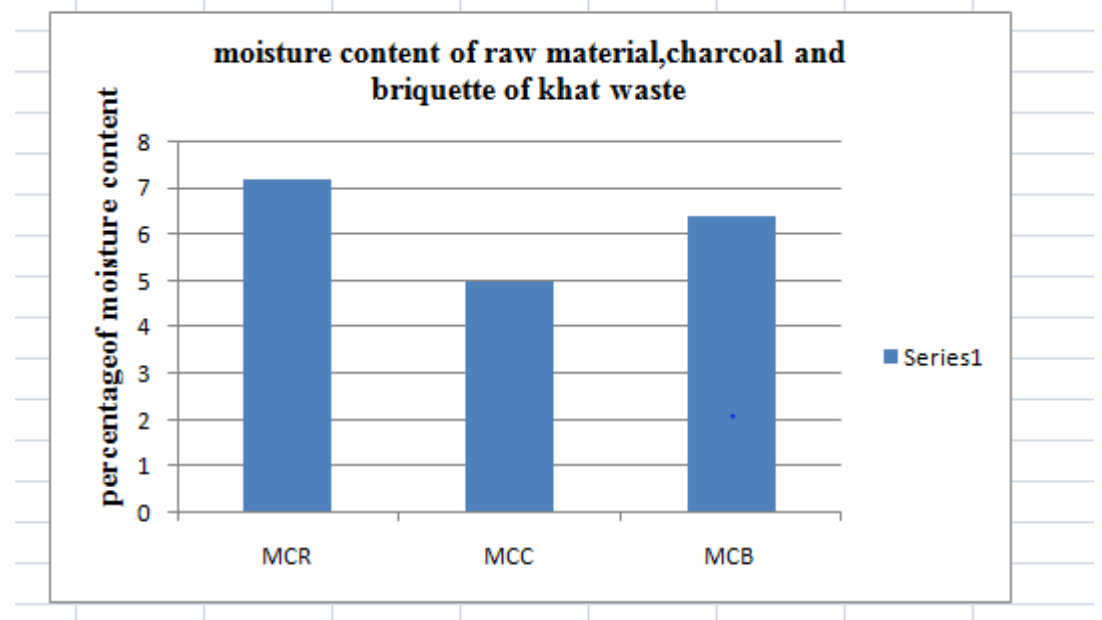

\subsection{Volatile matter}

Figure 4. Moisture content of raw material, charcoal and briquette

The volatile matter of briquettes in this study Table 3 is lower than the volatile matter of briquette produced from Coconut pith briquette and Sawdust briquette which have the matching values of 71 and $60 \%$, respectively. The higher the volatile matter implies the faster will be the ignition but with high smoke. Hence the briquette produced in this study is contributing minimal indoor air pollution due to their small amount of smoke generation during combustion relatively as they compared with briquettes produced from Coconut pith and Sawdust. Volatile matter in charcoal can vary from a high value of $40 \%$ or more down to 5\% or less than 5\% (FAO, 1985). Good quality charcoal should have volatile matter range from 20 to 25\% (FAO, 1987). As shown in Figure 7 the raw material of khat waste branch in this study the highest volatile matter with $68.51 \%$ and its briquette $24.862 \%$, which fit within the desirable criteria set by (FAO, 1987).

Table 3. Volatile mater of raw material and briquette

\begin{tabular}{|c|c|c|}
\hline No & VM tested & VM value (\%) \\
\hline 1 & $\begin{array}{c}\text { Volatile Mater of Raw Material } \\
\text { (VMR) }\end{array}$ & 68.51 \\
\hline 2 & $\begin{array}{c}\text { Volatile Mater of Briquette } \\
\text { (VMB ) }\end{array}$ & 24.862 \\
\hline
\end{tabular}

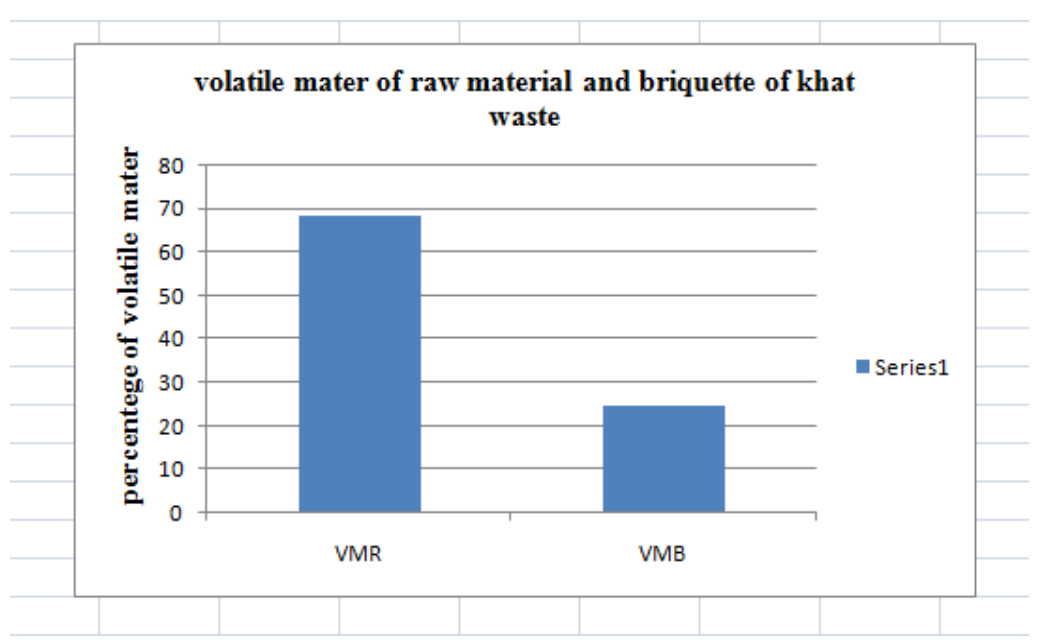

Figure 5. Volatile mater of raw and briquette waste of khat

\subsection{Ash Content}

In this study, clay soil was used, which is non-combustible during ignition and this is why high amount of ash content was found. The lower the ash content the better will be the briquette for utilization and the higher the ash content the higher will be the formation of dust and it affect the combustion efficiency. As observed from figure 5 above briquette of khat waste with higher Ash value meaning low quality fuel as compared to row material of khat waste. The ash content of the briquettes in this study Figure 5 is higher than the ash content of briquette produced from elephant grass and spear grass which have the values of 4.35 and $6.09 \%$, respectively. The higher ash content might be due to the binder type that we were used. 
International Journal of Advances in Scientific Research and Engineering (ijasre), Vol 5 (3), March-2019

Table 4: Ash content of raw material and briquette

\begin{tabular}{|c|c|c|}
\hline No & AC tested & AC value (\%) \\
\hline 1 & $\begin{array}{c}\text { Ash Content of Raw Material } \\
\text { (ACR) }\end{array}$ & 3.39 \\
\hline 2 & $\begin{array}{c}\text { Ash Content of Briquette } \\
\text { (ACB) }\end{array}$ & 29.4 \\
\hline
\end{tabular}

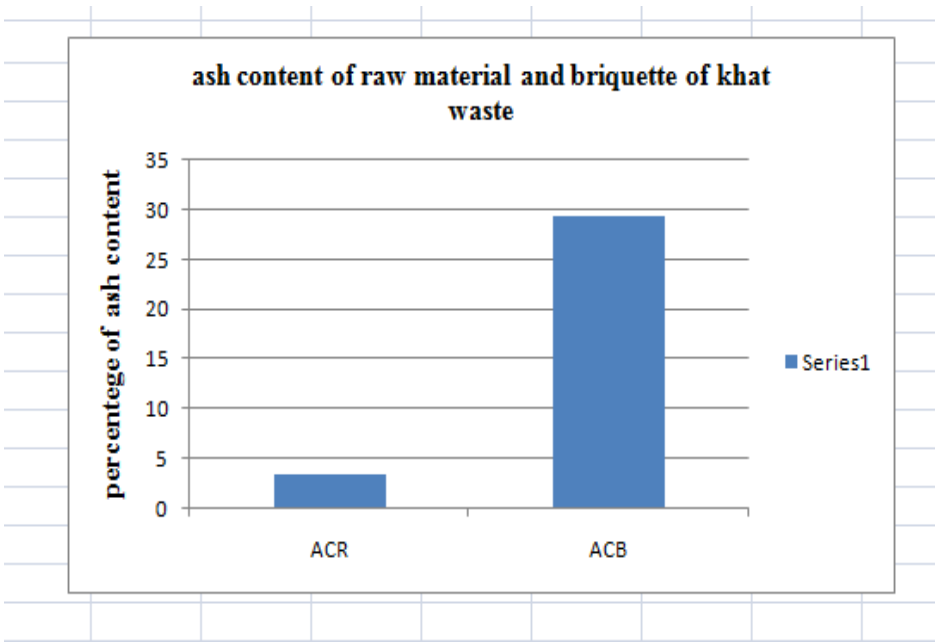

Figure 6. Ash content of raw material and briquette of khat waste

\subsection{Fixed Carbon Content}

A fixed carbon content of the briquette is the solid combustible residue that remains after the briquette was heated and the volatile matter was removed. The fixed carbon contents of briquettes in this study is greater than the fixed carbon content of briquette produced from wood which have the equivalent value of $1.6 \%$. Fixed carbon content of the row material and briquette produced in this study also differed significantly between row material and briquette produced from branch khat waste. The high fixed carbon content gives the result of high calorific value (FAO, 1985). It seems true where the produced fuel briquette and row material had higher fixed carbon content of 20.9 and 39.268 and had the higher gross calorific value of 3688.3946 and $4143.2549 \mathrm{cal} / \mathrm{g}$ ,respectively. The fixed carbon of raw material of khat waste $20.9 \%$ and for briquette, it was about $39.268 \%$. Thus, the charcoal contains slightly carbon.

Table 5: Fixed carbon content of raw material and briquette khat waste

\begin{tabular}{|c|c|c|}
\hline No & FCC tested & FCC value (\%) \\
\hline 1 & $\begin{array}{c}\text { Fixed Carbon Content of Raw } \\
\text { Material (FCCR ) }\end{array}$ & 20.9 \\
\hline 2 & $\begin{array}{c}\text { Fixed Carbon Content Of Briquette } \\
\text { (FCCB ) }\end{array}$ & 39.268 \\
\hline
\end{tabular}

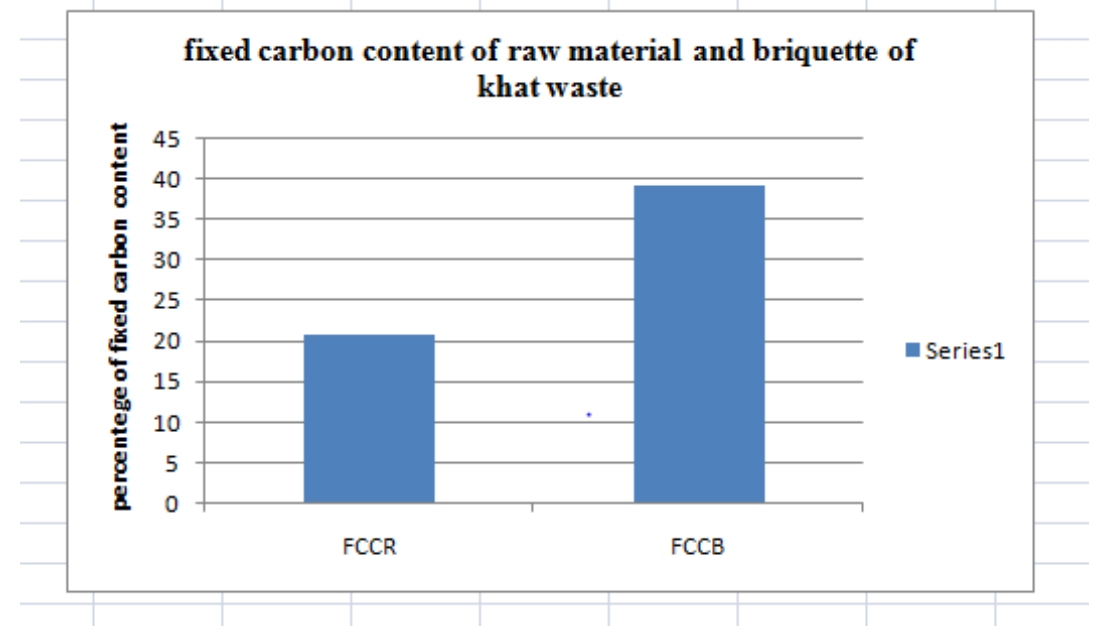

Figure 7. Fixed carbon content of raw material and briquette of khat waste 


\subsection{Combustion and Heat Efficiency Test of Khat Waste Fuel Briquette}

Production of high quality charcoal briquettes demands that a suitable binder is used and sufficient pressure. Such that the physical characteristics are comparable with or even are better than wood charcoal. In mechanized units starch is the preferred binder as it has very good binding property and also when combusted produce no smell or smoke but using clay as binder will yield much more clean and low cost fuel briquette than starch or molasses one. The result for combustion test, flame and heat efficiency test of the produced khat waste fuel briquette confirmed that there is no smoke (smoke free) except at a startup. No spark formation,, no soot production, no smell or odor and strong heat which can boil one liter water in less than 15 minute and two liter water with less than 25 minute, respectively. Therefore, durability fuel briquette is its one advantage than other form of fuel charcoal further more predicting the practical cooking time is the important aspect in energy efficient way utilization and for a better way utilization and efficient application or usage of the produced khat waste fuel briquette and from practical cooking study done. Up on practical cooking laboratory experiment done, once the fuel briquette fired it is not possible to quit the fire for moment, there for, knowing the proper cooking time enable to minimize energy loss and even save money and time. This boiling test Accor in the Laboratory at Alternative Energy Development and Promotion Directorate Laboratory with room and water temperature $19.7{ }^{\circ} \mathrm{C}$ and $18.6{ }^{\circ} \mathrm{C}$ respectively. Thus detail test parameter is shown in table. Also in table shown below the temperature, variation in every ten minute is interval until end of ash was shown in detail below. However, during this testing experiment similar stove have different weight because it has an error during manufacturing. Thus, difference cause durability of burning which was stove that has higher weight has higher of burning.
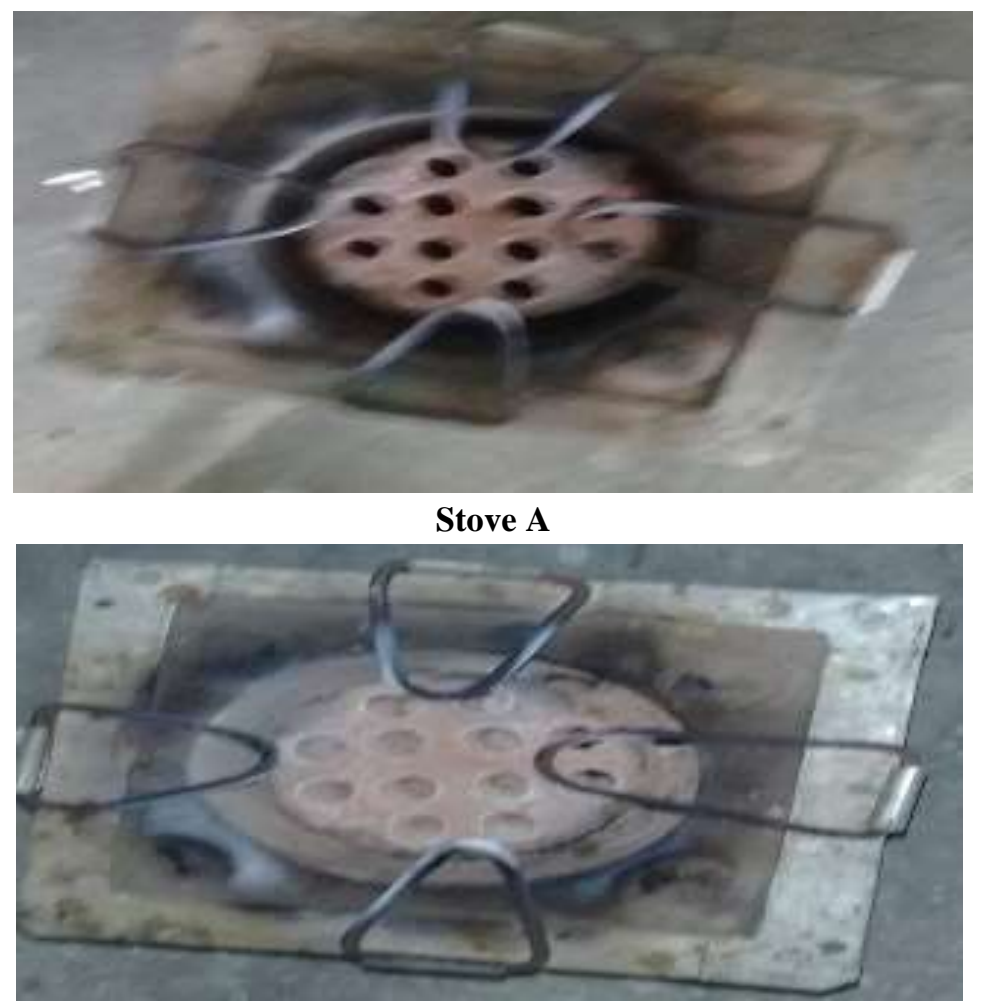

Stove B

Figure 8. Compression of two stoves

Table 6: list of material to boiling test of $1 \mathrm{~L}$ and $2 \mathrm{~L}$ water

\begin{tabular}{|l|l|c|c|}
\hline No & \multicolumn{1}{|c|}{ Parameters } & $\begin{array}{c}\text { For 1L weight in gram } \\
\text { (Stove A) }\end{array}$ & $\begin{array}{c}\text { For 2L weight in gram } \\
\text { (Stove B) }\end{array}$ \\
\hline 1 & Stove weight & 4494.5 & 3714.5 \\
\hline 2 & Container weight & 186 & 196 \\
\hline 3 & Briquette weight & 370 & 412 \\
\hline 4 & Container weight with water & 1257.5 & 2492.5 \\
\hline 5 & Container weight with water at boiling point & 1140 & 2146.5 \\
\hline 6 & Container weight with water at end of boiling & 340.5 & 1575.5 \\
\hline 7 & Stove weight with ash of briquette at end & 4568 & 3776.5 \\
\hline
\end{tabular}




\section{CONCULISION}

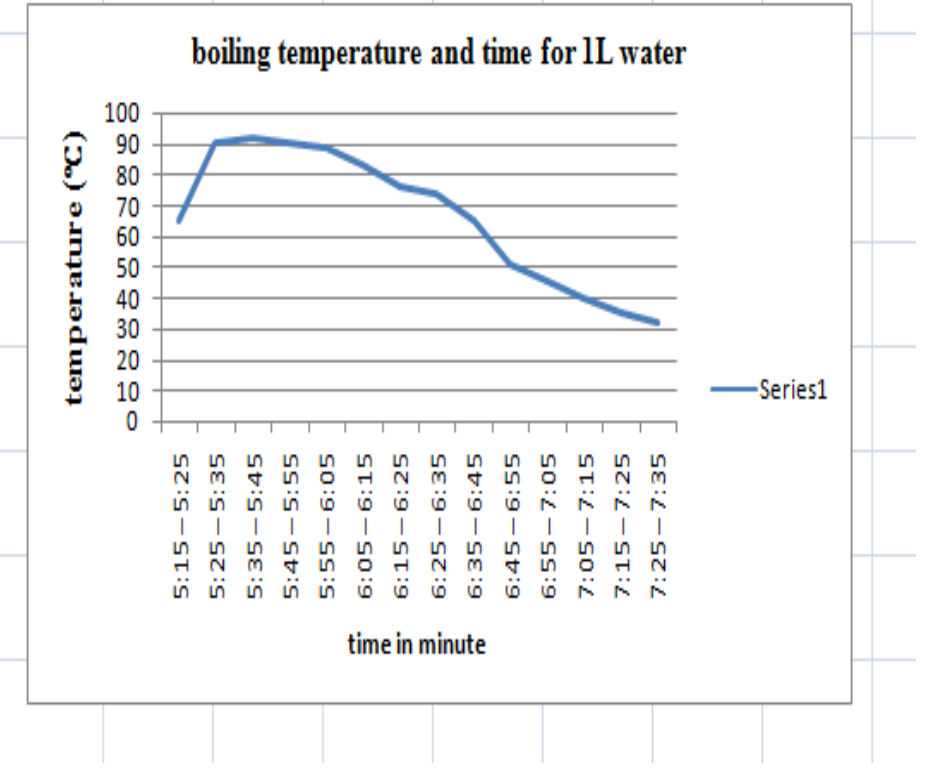

Figure 9: Boiling test for 1L water

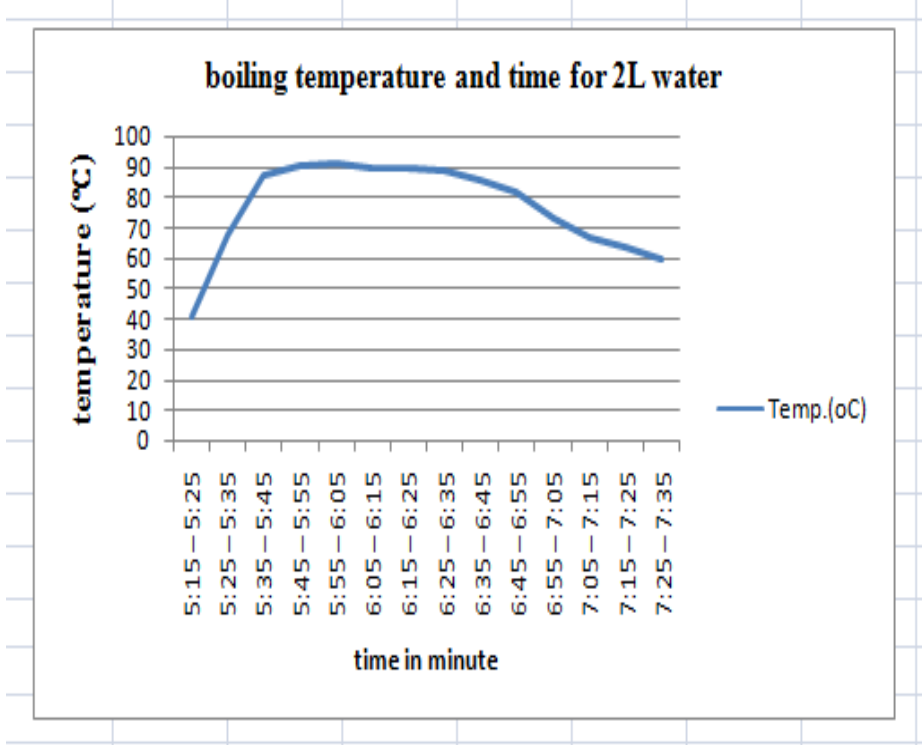

Figure 10: Boiling test for $2 \mathrm{~L}$ water

This study showed that raw material and briquette produced from khat waste was found as quality sources of energy. Because, raw material and briquettes have higher caloric $3688.3946 \mathrm{cal} / \mathrm{g}$ and $4143.269 \mathrm{cal} / \mathrm{g}$ respectively, medium fixed carbon content $20.9 \%$ and $39.268 \%$, respectively, medium volatile matter $68.51 \%$ and $24.862 \%$,respectively, medium moisture $7.2 \%$ and $6.4 \%$,respectively and low ash contents $3.39 \%$ and medium , $29.4 \%$ respectively. Similarly, utilization of khat waste as source of energy in terms of briquette production deliver clean energy that reduce indoor air pollution and respirator infectious disease that occurred due to the release of smoke during cooking. Besides, can solve the rural and urban household energy by supplying a clean renewable energy and reduce forest degradation. The physical and chemical analysis of raw material and fuel briquette produced from khat waste were found a promising product can be obtained from khat that can be generate income and job opportunity to the local community and micro enterprise. Therefore, based on this finding using invasive waste like khat waste for clean renewable energy enable possible weed management option as well as increase farmer's crop production by allowing user free lands disposal.

\section{REFERENCES}

[1]. Charcoal Briquette Production Using Orange Bagasse and Corn Starch (by Karine Zanella*a, José L. Gonçalvesb, Osvaldir P. Tarantoa

[2]. Reed, T.B., Trefek, G, and Diaz, L. (1980). Biomass densification energy requirements in thermal conversion solid wastes and biomass, American Chemical Society, Washington D.C. 
[3]. Brenden O. (1985) Pharmacological aspects of the chewing of khat leaves. Pharmacol Rev; 37:149-164.

[4]. Malatji,P., Mamphweli,N.S. and Meincken,M., (2011). The technical pre-feasibility to use briquettes made from wood and agricultural waste for gasification in a downdraft gasifier for electricity generation. Journal of Energy in Southern Africa. Vol. 2, No.4: pp.1-7.

[5]. Oladeji, J., (2010). Fuel Characterization of Briquettes Produced from Corncob and Rice Husk Resides. The Pacific Journal of Science and Technology, Vol. 11, No.1:pp.101-106.

[6]. Yisak Seboka and Mequanint Negusse., (2006). Laboratory Test Results on Charcoal and Charcoal Briquettes Made From Selected Trees and Agro-Industrial Wastes. Report 56 submitted to Ethiopian Rural Energy Development and Promotion Centre Addis Ababa, Ethiopia.Pp.103-169. 